\title{
Deposition of silicon films in presence of nitrogen plasma- A feasibility study
}

\author{
SHEETAL J PATIL, DHANANJAY S BODAS, G J PHATAK ${ }^{\dagger}$ and S A GANGAL* \\ Department of Electronic Science, University of Pune, Pune 411 007, India \\ ${ }^{\dagger}$ Centre for Materials for Electronics Technology (C-MET), Pune 411 008, India
}

MS received 7 September 2001

\begin{abstract}
A design, development and validation work of plasma based 'activated reactive evaporation (ARE) system' is implemented for the deposition of the silicon films in presence of nitrogen plasma on substrate maintained at room temperature. This plasma based deposition system involves evaporation of pure silicon by e-beam gun in presence of nitrogen plasma, excited by inductively coupled RF source $(13.56 \mathrm{MHz})$. The activated silicon reacts with the ionized nitrogen and the films get deposited on silicon substrate. Different physical and process related parameters are changed. The grown films are characterized using X-ray diffraction (XRD), scanning electron microscopy (SEM) and ellipsometry. The results indicate that the film contains silicon nitride and a phase of silicon oxy nitride deposited even at room temperature. This shows the feasibility of using the ARE technique for the deposition of silicon films in nitrogen plasma.
\end{abstract}

Keywords. Silicon nitride ( $\beta$-phase); ARE; XRD; SEM; ellipsometry.

\section{Introduction}

Silicon nitride is one of the promising materials for numerous applications in the semiconductor industry (Hirohata et al 1994). The application of silicon nitride for passivation in packaging, in order to reduce the manufacturing cost of the VLSI devices, is preferable due to its superior resistance to moisture penetration (Martinet et al 1983; Ibok et al 1994). In these applications, the temperature limitation imposed by the metal and the other processes necessitates a low temperature film preparation method. Silicon nitride has to be deposited at a low temperature below $300^{\circ} \mathrm{C}$ for passivation application.

Silicon nitride can be prepared by various methods such as low pressure CVD (LPCVD), plasma-enhanced CVD (PECVD), laser assisted photo CVD, ion implanting and DC and RF sputtering (Kern and Schnable 1979; Cotler and Chapple Sockol 1993; Chin and Elsner 1975; Martin and Exarhos 1985). In LPCVD and PECVD techniques, the films are typically deposited using silane $\left(\mathrm{SiH}_{4}\right)$ and ammonia $\left(\mathrm{NH}_{3}\right)$ gas mixture at temperatures higher than $300^{\circ} \mathrm{C}$. Even though these techniques give good stoichiometry of the deposited films, the presence of 5-30 at.\% hydrogen, may be the cause of their high bulk trap densities (Franz and Langhinrach 1969). Such bulk trap in the gate dielectric assist the conduction of carriers, causing an increase in the gate leakage current

*Author for correspondence and make them unusable as gate dielectrics. These films also show poor thermal stability, as they are prone to the release of hydrogen at higher temperatures (Parson et al 1992). Thus it is evident that the incorporation of hydrogen renders the device unstable, whereas DC and RF

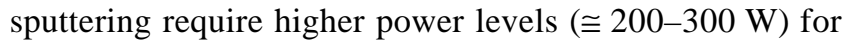
the deposition of the films.

A new plasma deposition technique, known as 'activated reactive evaporation (ARE)' is implemented for the deposition of silicon films in presence of nitrogen plasma with a view to deposit silicon nitride films. Compared to reactive sputtering, this method offers advantages of low power levels, higher deposition rates and is expected to offer all the advantages of PECVD eliminating problem of hydrogen content in the films.

ARE technique has been developed mainly for the deposition of tribological (Kern 1989), transparent and conducting (Fukkutonik et al 1984) coatings. It involves evaporation of metal in the presence of plasma of reacting gas. The 'activation' of the evaporated species as well as the gaseous reactant by plasma helps in depositing high quality compound films at very low temperatures. Coatings of $\mathrm{SnO}_{2}, \mathrm{In}_{2} \mathrm{O}_{3}$ and $\mathrm{CdO}$ have been reported using this technique (Nath and Bunshah 1980; Randhawa et al 1981; Phatak and Rakesh Lal 1994).

In the present work, an ARE system is developed for deposition of silicon films in presence of nitrogen plasma. This work refers to a low temperature deposition process. The evaporated silicon atoms react with excited/ionized nitrogen species on the substrate surface to form either silicon nitride or some other non-stoichiometric compound 
of silicon and nitrogen. An electron beam (e-beam) evaporation method is selected for the evaporation of pure silicon because of its precise evaporation control, relative cleanliness and high temperature achieved as required for silicon. ARE with e-beam gun evaporation has already been used for the deposition of silicon oxide (Bunshah 1989).

Here the main stress is given on the design, fabrication and validation of indigenously made ARE system for the deposition. In the present work, preliminary results on deposition of silicon nitride films in presence of nitrogen plasma on substrates at room temperature are reported for the first time. The characterization of the deposited films was done by X-ray diffraction (XRD), scanning electron microscopy (SEM) and ellipsometry.

\section{Design and fabrication of ARE system}

The plasma based 'activated reactive evaporation system' shown in figure 1 has been designed and fabricated in-house. The pumping system comprises of a rotarybacked diffusion pump having a liquid nitrogen trap between the diffusion pump and the chamber. E-beam gun is installed for the evaporation of pure silicon while nitrogen gas is excited by inductively coupled RF source (13.56 MHz frequency) through a matching network. Ebeam requires minimum pressure of about $10^{-4}$ Torr for its operation whereas to sustain the nitrogen plasma, minimum pressure required is up to $10^{-3}$ Torr. To match both these conditions, the system is divided into two major parts, high vacuum chamber (e-beam gun housing) and low vacuum chamber (plasma reactor) maintaining one order differential pressure. These chambers are connected by a separating plate having an opening diameter of $2 \mathrm{~cm}$, which is optimized in order to maintain the pressure difference mentioned above.

The high vacuum part houses an e-beam gun $\left(180^{\circ}\right.$, $3 \mathrm{~kW}, 5 \mathrm{kV})$, which evaporates silicon through a crucible kept $5 \mathrm{~cm}$ below the opening $(2 \mathrm{~cm} \mathrm{dia.)} \mathrm{connecting} \mathrm{the}$ two chambers. Placed above the separating plate is a $12 \mathrm{~cm}$ diameter glass chamber, which defines the low vacuum part of the system. Plasma is excited by the RF source through an inductive coil wound around the reaction chamber. The externally placed coils avoid their submersion into the plasma and the consequent contamination. The plate placed over the glass tube of the reaction chamber supports the substrate holder, contains the arrangement for pirani and penning gauges for pressure measurement, connections for heater, thermocouple and gas inlet. The heater allows carrying out the depositions at different substrate temperatures and thermocouples to monitor the temperature. The maximum vacuum attained in the fabricated system is $10^{-6}$ Torr and with the nitrogen gas flow about one order of magnitude difference in the pressure is maintained between the two chambers
( $\sim 10^{-3}$ Torr and $\sim 10^{-4}$ Torr). The system is tested for the deposition of silicon in presence of nitrogen plasma.

\section{Experiments on deposition of silicon in presence of nitrogen plasma}

The ARE system (figure 1) developed is further used for the deposition. The system was evacuated to $10^{-6}$ Torr. Ultra pure nitrogen gas was then introduced from the top into the reaction chamber of the system. The system was flushed with nitrogen gas for $10-15 \mathrm{~min}$ so as to minimize the residual gas content in the chamber. The nitrogen flow rate was set between 4 and $5 \mathrm{sccm}$ achieving the pressure in reaction chamber to $\cong 10^{-3}$ Torr and in ebeam gun chamber $\cong 10^{-4}$ Torr. The nitrogen gas was then excited by an inductively coupled RF source (13.56 MHz). Stable conditions were reached within 10-15 min. Silicon was then evaporated by e-beam gun, which enters in the nitrogen plasma region through $2 \mathrm{~cm}$ diameter opening. It further reacts with nitrogen ions to form silicon nitride or a compound of non-stoichiometric silicon and nitrogen and gets deposited as a film on the substrate. The details of deposition conditions are given in table 1.

In the present work, $n$-type (100) oriented silicon wafers having $3 \Omega \mathrm{cm}$ bulk resistivity are used as sub-

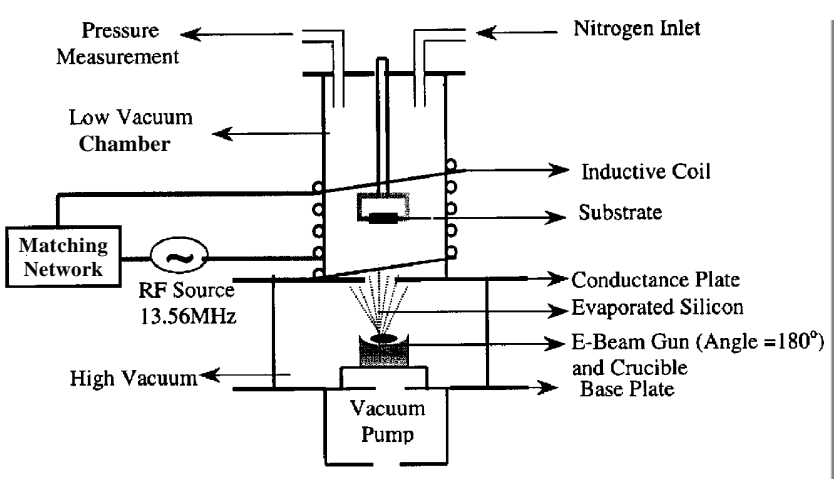

Figure 1. RF excited ARE system.

Table 1. Deposition conditions.

\begin{tabular}{ll}
\hline Deposition parameters & Values \\
\hline Substrate used & Silicon (100-n-Type) \\
Source material & Silicon powder (purity 99.999\%) \\
Substrate temperature & Room temperature \\
Source to substrate distance & $12 \mathrm{~cm}$ \\
Plasma reactor pressure & $10^{-3} \mathrm{Torr}$ \\
E-beam gun chamber pressure & $10^{-4} \mathrm{Torr}$ \\
E-beam gun current & $150 \mathrm{~mA}$ \\
E-beam gun acceleration voltage & $5 \mathrm{kV}$ \\
Nitrogen flow rate & $4.5 \mathrm{sccm}$ \\
RF plasma power & $80 \mathrm{~W}$ \\
Evaporation time & $25 \mathrm{~min}$ \\
\hline
\end{tabular}


strates. The substrates were de-oxidized using $\mathrm{HF} / \mathrm{HNO}_{3}$ and rinsed using $18 \mathrm{M} \Omega$ de-ionized (DI) water before loading in the system.

The structural characterization of these films was done using X-ray diffraction (XRD) technique [Philips, PW $1729, \mathrm{CuK} \alpha$ source]. Topography of the films was observed using scanning electron microscope (SEM) [Cambridge, Model SEM S120]. The refractive index and the thickness of the films was measured using elipsometry [Ellipsometer-Gaester L118 null].

\section{Results and discussion}

A series of experiments were carried out for checking the validity of the system and repeatability of the deposition of the films. Initial representative results are reported here. The X-ray diffraction patterns were taken in order to identify the material and evaluate the crystallinity of the deposited films. A typical XRD pattern of the film deposited at $80 \mathrm{~W}$ RF power is shown in figure 2. The pattern shows a strong peak corresponding to silicon substrate $\left[2 \theta=69 \cdot 11^{\circ}\right]$. Since the films are deposited on single crystalline silicon (100 orientation) substrate, this expected peak is neglected from rest of the analysis. The other peaks at $2.698 \AA, 1.501 \AA, 1.340 \AA$ ' $d$ ' values correspond to either silicon nitride or silicon oxynitride (Inorganic Powder Data 1993). The low intensity of these peaks as compared to that of silicon peak may be attributed to

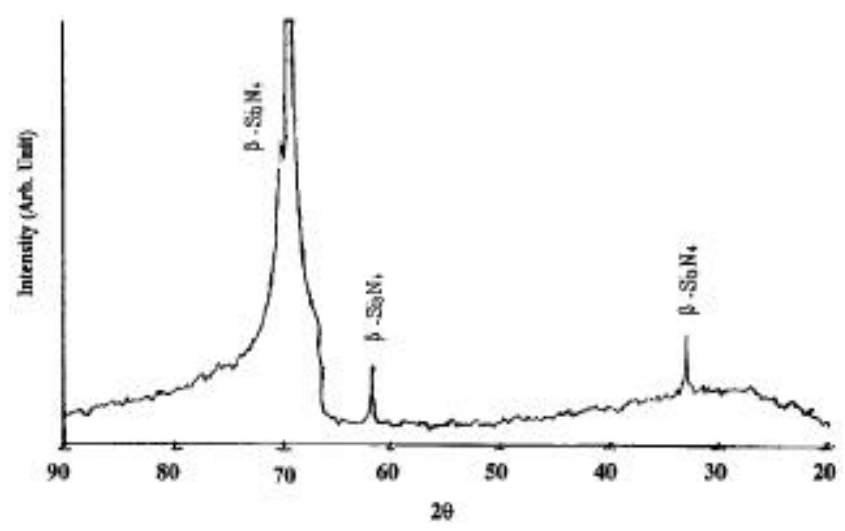

Figure 2. XRD plot of the film deposited at $80 \mathrm{~W}$ RF plasma power. the smaller thickness of the film. The percentage differences $([d(\mathrm{std})-d(\mathrm{obs}) / d(\mathrm{std})] \times 100)$ of observed peaks from the standard peaks calculated for silicon nitride $(\beta$ phase) and silicon oxynitride are given in table 2 . It is evident from table 2 that, the difference observed in the data for silicon nitride is less as compared to that for silicon oxynitride.

The refractive index (He-Ne laser wavelength $632.8 \mathrm{~nm}$ ) and thickness of the films were obtained from ellipsometric analysis. Refractive index was found to be 1.97 , which is very close to the standard value of silicon nitride $(\eta=2)$ (Sze 1988) and the thickness obtained was $800 \AA$. The deviation of $\eta$ from the standard value may be because of the non-stoichiometry of the films and/or incomplete formation of silicon nitride/oxide/oxynitride. Exact reasons are being investigated.

The surface topography of the deposited films was observed using scanning electron microscope (SEM). The SEM pictures of the films are shown in figures $3 a-b$. The films were observed without any conducting film coating, and therefore, the large difference in the contrast of the film and the silicon substrate and the charging effects observed during experiment indicates insulating nature of the film. The variation of the film thickness near the edge of the film on the entire substrate was observed. Figure $3 \mathrm{a}$ shows the surface texture of same film at $942 \times$ magnification. Particulate deposition of size between $0.5 \mu \mathrm{m}$ and $10 \mu \mathrm{m}$ diameter was seen over the entire film, which make the film texture rough. These particles on the surface of the film were seen under the spot EDAX. It is confirmed that the particles are of silicon. Particulate deposition of silicon may be due to the incomplete formation of nitride at the end of deposition. In order to check the adhesion of these silicon particles, the film was subjected to ultrasonic agitation. It was found that, these particles are having extremely poor adhesion and could be easily removed ( $\mathrm{Hu}$ 1966). Micrograph of the film after ultrasonic removal of loosely bound particles is shown in figure $3 \mathrm{~b}$. The film surface is observed to be smooth and some black pinholes appear on the film at the places where probably above mentioned silicon particles were present before.

In order to cross check the chemical composition, the ultrasonically treated films were analysed by XRD again, which shows no appreciable change from the diffraction

Table 2. \% Difference of observed XRD peaks from standard (film deposited on silicon $\left(\begin{array}{lll}1 & 0 & 0\end{array}\right)$ at $80 \mathrm{~W}$ plasma power).

\begin{tabular}{lcccc}
\hline $\begin{array}{l}\mathrm{Std} \text { ' } d \text { ' values } \\
(\AA) \text { and }\langle h k l\rangle\end{array}$ & $\begin{array}{c}\mathrm{Std} \text { ' } d \text { ' values } \\
(\AA) \text { and }\langle h k l\rangle \\
\mathrm{Si}_{2} \mathrm{~N}_{2} \mathrm{O}\end{array}$ & $\begin{array}{c}\text { Observed ' } d \text { ' } \\
\text { values } \\
(\AA)\end{array}$ & $\begin{array}{c}\% \text { difference } \\
\mathrm{Si}_{3} \mathrm{~N}_{4} \\
(\beta-\text { Phase })\end{array}$ & $\begin{array}{c}\text { \% difference } \\
\mathrm{Si}_{2} \mathrm{~N}_{4} \mathrm{O}\end{array}$ \\
\hline $2.66\left(\begin{array}{lll}1 & 0 & 1\end{array}\right)$ & $2.60\left(\begin{array}{lll}1 & 3 & 0\end{array}\right)$ & 2.680 & 0.75 & 3.07 \\
$1.51\left(\begin{array}{lll}3 & 2 & 0\end{array}\right)$ & $1.52\left(\begin{array}{lll}1 & 1 & 3\end{array}\right)$ & 1.501 & 0.9 & 1.25 \\
$1.34\left(\begin{array}{lll}3 & 2 & 1\end{array}\right)$ & $1.32\left(\begin{array}{lll}4 & 0 & 1\end{array}\right)$ & 1.344 & 0.29 & 1.81 \\
\hline
\end{tabular}



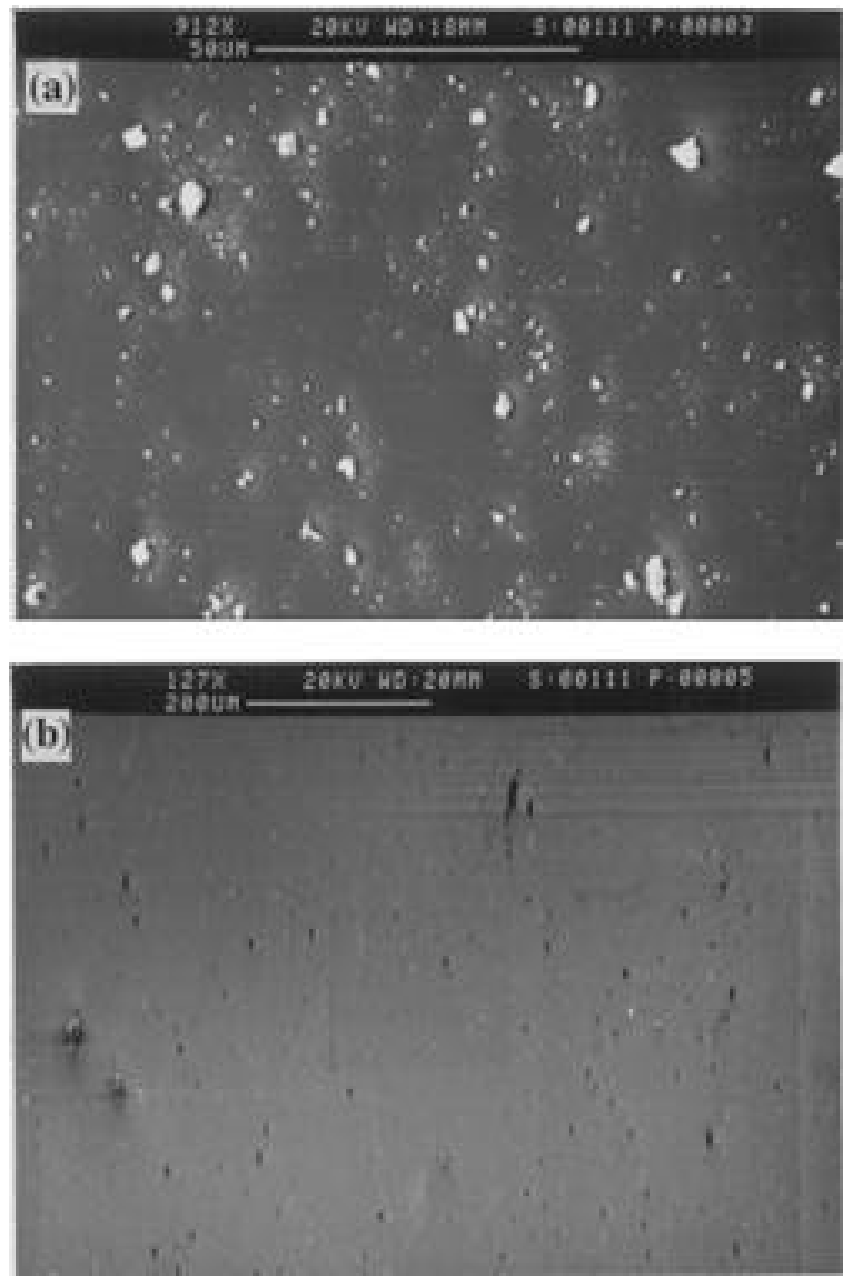

Figure 3. SEM pictures of the deposited silicon nitride film: a. surface texture and $\mathbf{b}$. film texture after ultrasonic treatment.

pattern before ultrasonic treatment. This confirms that the film indeed is composed of silicon nitride ( $\beta$-phase) and silicon oxynitride.

\section{Conclusions}

The deposition of silicon films in nitrogen plasma has been carried out by ARE process on substrates maintained at room temperature. The preliminary result shows the formation of silicon nitride and a phase of silicon oxynitride having some particulates of silicon on the surface. Thus the feasibility of deposition of silicon films by in-house designed and fabricated ARE system has been demonstrated. Further, the work on optimization of deposition parameters is being carried out.

\section{Acknowledgements}

The authors are grateful to the funding agency BRNS, Mumbai, for support in the course of the study. Sincere thanks to Dr Murali Sastry, National Chemical Laboratory, Pune, for providing ellipsometry facility.

\section{References}

Bunshah R F 1989 Thin Solid Films 10721

Chin J and Elsner N B 1975 J. Vac. Sci. Technol. 12821

Cotler T J and Chapple Sockol J 1993 J. Electrochem. Soc. 140 2071

Hirohata Y, Shimamoto N, Yamashima T and Yabe K 1994 Thin Solid Films 425-9 253

Hu S M 1966 J. Electrochem. Soc. 113693

Franz I and Langhinrach W 1969 Solid State Electron. 12955

Fukkutonik M, Fujitsuka M and Okada M 1984 Thin Solid Films 120283

Ibok E, Santana M, Garg S and Kapoor V J 1994 The electrochem. soc. proc. (ed.) W D Brown (NJ: Pennington) p. 385

Inorganic Powder Data 1993 JCPDS ICDD, USA

Kern W 1989 in Microelectronics materials and processes (ed.) R A Levy (The Netherlands: Kluwer Academic Publishers) p. 247

Kern W and Schnable G L 1979 IEEE Trans. Electron. Dev. 26647

Martin P and Exarhos G J 1985 J. Vac. Sci. Technol. A3 615

Martinet F, Guegan G, Jesionka J C and Kapoor V J 1983 The electrochem. soc. proc. (ed.) W D Brown (NJ: Pennington) p. 190

Nath P and Bunshah R F 1980 Thin Solid Films 6963

Parson G N, Souk J H and Batey J 1992 J. Appl. Phys. 13482

Phatak G and Rakesh Lal 1994 Thin Solid Films 24517

Randhawa S H, Mathews M D and Bunshah R F 1981 Thin Solid Films 83267

Sze S M 1988 VLSI technology (New York: McGraw Hill Co.) p. 261 